\title{
Fostering a sustainable pediatric cardiac workforce in the developing world during the current COVID-19 pandemic
}

\author{
John S. K. Murala ${ }^{1}$, Stephany Kim², Tom R. Karl $^{3}$, A. Thomas Pezzella ${ }^{4}$ \\ ${ }^{1}$ Cardiothoracic Surgery, University of Texas Southwestern Medical Center, Dallas, TX, USA; ${ }^{2}$ University of Texas Southwestern Medical School, \\ Dallas, TX, USA; ${ }^{3}$ European Journal of Cardio-Thoracic Surgery, University of Queensland and Queensland Pediatric Cardiac Service, Queensland, \\ Australia; ${ }^{4}$ Founder/Director International Children's Heart Fund, Worcester, MA, USA \\ Contributions: (I) Conception and design: JSK Murala, AT Pezzella; (II) Administrative support: S Kim; (III) Provision of study materials or patients: \\ All authors; (IV) Collection and assembly of data: JSK Murala, S Kim; (V) Data analysis and interpretation: All authors; (VI) Manuscript writing: All \\ authors; (VII) Final approval of manuscript: All authors. \\ Correspondence to: John S. K. Murala, MD. Assistant Professor in the Department of Cardiovascular and Thoracic Surgery, Surgical Director of \\ ex vivo lung perfusion (EVLP) Program, Department of of Cardiovascular and Thoracic Surgery, University of Texas Southwestern Medical Center, \\ 5959 Harry Hines Blvd., $10^{\text {th }}$ Floor, Suite HP10.110, Dallas, TX 75390, USA. Email: john.murala@utsouthwestern.edu.
}

\begin{abstract}
The majority of the world's population with congenital heart disease (CHD) does not have access to corrective surgery, including $70 \%$ of those living in sub-Saharan Africa. Communicable diseases still cause significant mortality in low- and mid-income countries (LMICs), but increasingly, the burden of noncommunicable diseases (NCD), such as CHD and rheumatic heart disease (RHD), has increased, creating great strain on fragile healthcare systems. The number of pediatric cardiac centers in LMICs is grossly inadequate to provide the necessary care. The unprecedented COVID-19 pandemic due to SARS-CoV-2 has only worsened the global disparities, and unfortunately has set the clock back by a few years. There has been an interruption of foreign missions and collaborations, which has affected the care of children with heart disease, and which will further increase the number on the waitlist. Much of the hard-won progress made in improving neonatal, infant, and maternal mortality may be lost due to the pandemic. Time is running out for the ambitious sustainable development goals set for 2030. At present, only $1 \%$ of developing world are vaccinated against COVID-19 with the poorest countries not expected to receive vaccine until 2023. This intervening time provides a crucial opportunity to apply "frugal innovation" by training and equipping local teams and policy makers. We employed a Gap and SWOT analysis to identify the steps needed to work towards improving children's heart care in the developing world, all while using lessons learned from the COVID-19 pandemic.
\end{abstract}

Keywords: Cardiac disease; children; congenital; low- and mid-income countries (LMICs); COVID-19; pandemic; rheumatic heart disease (RHD)

Received: 27 July 2021; Accepted: 22 September 2021; Published: 30 March 2022.

doi: 10.21037/asj-21-72

View this article at: https://dx.doi.org/10.21037/asj-21-72

\section{Introduction}

In low-and mid-income countries (LMICs), there has been an increase in the prevalence of non-communicable disease (NCD) to epidemic proportions (1). Deaths from NCD number almost 41 million annually, comprising almost $71 \%$ of deaths globally (WHO). The incidence of congenital heart disease (CHD) is $8-12 / 1,000$ live births (1). Similarly, the prevalence of acquired heart disease [mostly rheumatic heart disease (RHD)] in children in Africa is from 2.7 to 20/1,000 population (2). The burden of RHD is not restricted to sub Saharan Africa. China, India, Pakistan, and Indonesia collectively account for $72 \%$ of the mortality rate due to RHD. It is estimated that about 1.3 million children are born with CHD every year in the world $(1,2)$. Unfortunately, $90 \%$ of these children do not have access 
to medical care, with the majority living in LMICs (2). Of those, $70 \%$ are projected to be in sub-Saharan Africa (3). According to the global burden of disease, the estimated number of deaths from CHD in 2017 was 261,247 (CI: $216,567-308,159)$ and the estimated disability adjusted life years (DALY) due to CHD was 22,223,897 (CI: 18,066,81126,578,182) (4).

Presently, there is one cardiac center per 120,000 population in the US, but only one per 33 million in Africa (5). Hence, mortality from congenital and acquired heart disease is high, and is compounded by other communicable diseases to which these children are susceptible (6). Surgery for CHD is very specialized, and acquiring the requisite skills involves many years of training and operative experience. Currently, internationally standardized criteria for training in pediatric heart surgery do not exist. There is a striking disparity in various regional and national criteria, standards, and requirements (7). It is clear that establishing global standardized criteria for pediatric heart surgery training and certification is crucial to promoting quality care globally.

We have discussed many of the above challenges previously (8). The current COVID-19 pandemic due to SARS-CoV-2 has changed the way we need to look at the global disparities of pediatric heart surgery and the means to tackle them.

\section{Black swan event}

The present COVID-19 pandemic is a "black swan" event, an once-in-a-lifetime scenario causing major healthcare disruption. This pandemic has affected all health care services, and has complicated the care of CHD in many countries $(9,10)$. The pandemic has triggered an alarm in emergency preparedness and immunization services (11). A recent WHO study showed that in $94 \%$ of countries all the health staff working in areas of NCDs have been reassigned to COVID-19 pandemic care (12). Not surprisingly, the majority of cardiac surgical missions have halted their operations. Teams may resume missions on a case-bycase basis, using COVID-19 precautions (fully vaccinated team, testing of the patients and relatives) to full capacity, however, with wide travel restrictions, it may take a few years for resumption of all pre-pandemic missions. The issue goes beyond performing surgery in a safe and sterile environment. Many patients go back to communities with widespread viral load that make them even more vulnerable. Data for the adults show that the infection is very serious and mortality is very high amongst patients who developed COVID-19 after cardiac surgery $(13,14)$.

The inflammatory derangement following cardiac surgery blunts the symptoms and makes diagnosis of COVID-19 infection difficult $(13,14)$. They recommend strict safety norms and prolonged post-operative monitoring following cardiac surgery.

We can only assume this true in children also. It is necessary that visiting teams ensure that children after surgery can return to safe environments, where they have a low risk of contracting COVID-19 infection. Hence, this will also depend on how soon many of these countries can vaccinate their populations. Many healthcare systems, already burdened by the pandemic, have experienced inadequate care for NCDs (that include CHD) $(9,10)$. The waitlists for cardiac surgery have increased. While this is true with many advanced countries, the situation is even graver in LMICs.

So where do we see things moving from here? What is the future of global heart care? This review looks at the issues and suggest ways in which the seemingly hopeless situation can be used to our advantage. Prior to the pandemic, a number of priorities were set forth in the form of the Cape Town declaration and Sustainable Development Goals (SDG) $(15,16)$. Goal number 3 focuses on "[ensuring] healthy lives and [promoting] well-being for all at all ages" by 2030 (16). Specifically, SDG goal 3.2 is to end preventable deaths of newborns and children under 5 years of age, with all countries aiming to reduce neonatal mortality to at least as low as 12 per 1,000 live births and under-5 mortality to at least as low as 25 per 1,000 live births by 2030 (16). Similarly, SDG 3.4 goal aims to reduce by one-third premature mortality from NCDs through prevention, treatment, and promotion of mental health and well-being by 2030 (16). Prior to the pandemic, almost 121 countries had reached the under-5 SDG targets and 21 more countries are expected to achieve the same by 2030 . However, 53 other countries, most of them in sub-Saharan Africa, need much more help to reach these goals (11). Additionally, the pandemic has interrupted childhood immunization programs in almost 70 countries (16). It is estimated that there will be a $100 \%$ increase in malaria deaths and about 118 LMICs could see an increase of 9.8 to 44.8 percent in under-5 mortality per month (11). Many of these children will be those with CHD. In this paper, we will discuss the present situation of pediatric cardiac surgery in LMICs and possible solutions if we are to reach the SDG of 2030 in the wake of the COVID-19 pandemic. 


\section{Lessons from the pandemic}

The experiences with the Spanish flu led to improvements in public health, health education, isolation, sanitation, surveillance, and knowledge of transmission of influenza (17). It brought public health out of obscurity and ushered in a new age of international cooperation on health. Governments and policy makers can learn from the previous pandemics to come up with effective interventions for the current one (18). More recently, there are many lessons that LMICs can learn from the initial COVID-19 pandemic response in China, Italy and USA (19).

The lessons include diversion of resources to healthcare and research, effective border control, proactive improvement of risk communication, health promotion and education, effective price regulation, public aid, effective disease surveillance and finally having a strong political will (19). LMICs will do well by concentrating their limited resources on preventive measures and learning from the mistakes of the responses from other countries (19).

While no one is sure when normality will return, one can relate to what the pandemic has taught the world: resilience. With lockdown mandates forcing people inside their own homes, many had to work remotely to support themselves. Group gatherings were no longer possible, and large lectures became a health hazard. From this emerged Zoom, an online video-call platform that was not known by the majority of people in the world, now a household name (20). What was thought to be not possible remotely has been made possible today with technology. The questions to ask are what can be done with the newly emerging technology? How can we teach in the future? How can units be made self-reliant? Can this technology be used to help surgical units in the developing world become self-reliant?

The COVID-19 pandemic has also amplified the global health inequities and brought global health to the forefront. Global health is "an area for study, research, and practice that places a priority on improving health and achieving equity in health for all people worldwide" (21). It has largely moved away from the old school of thought of needing more policies and programs, and working in poor countries with high disease burden, to a more nuanced interpretation of global health risks whether in a rich or poor country (22). The focus is more on the scope of the problem rather than the location (rich or poor country), with focus on "globalization at the local level" and the knowledge that healthcare of a population has inherent global causes and consequences $(22,23)$. The focus is more on intentions, implementation, selection of the right intervention, and reaching the right target population $(22,23)$. So global health can address both domestic issues as well as international health. While the pandemic is raging across the world, there is a call for "decolonizing global health" with the need for a paradigm, leadership, and knowledge shift and a call for more geopolitical engagement to address existing health disparities (24).

Surgical training has also been impacted by the COVID-19 pandemic. Most residency programs are time based rather than competence based, so with wide disruptions to elective cases precious time has been lost. While online platforms have been used for didactics and conferences, the hands-on surgical training has been reduced, with one wondering if there will be an extension of training periods to achieve adequate competence (25).

The pandemic has made us a global village. Two of the authors (JSM and TK) remember that in the inaugural general body meeting of the WSPCHS in 2008, there was a discussion on what the annual membership fees should be. It was decided to be an $\mathrm{x}$ amount. Most of the people in the room felt it was reasonable. However, one surgeon from a LMIC stood up and said that the amount was equivalent to one month's salary for him. They could never forget the silence in the room. Often in the developed world, it is hard to fathom the problems of the LMIC, even for experienced caregivers.

We have been urged to integrate public health into medical education (26). A major paradigm shift in medical education is vital in order to develop health professionals that will focus on integrating public health to improve healthcare overall (26).

Table 1 describes some of the lessons from the pandemic and how we may apply them to care of children with CHD.

\section{Gap analysis}

\section{Current state}

LMICs include very diverse countries. On one hand, we have countries such as India, China, and Brazil, which have some good pediatric cardiac centers, and then there are wide-ranging countries in sub-Saharan Africa and Caribbean where there are no centers at all. Therefore, it will be difficult to generalize all LMICs. Taking India as an example, there are 150,000-200,000 children born with CHD each year and nearly 50,000 need immediate neonatal care. (27). However, less than $10 \%$ receive necessary 
Table 1 Lessons during the pandemic and areas for application

\begin{tabular}{|c|c|c|}
\hline No. & Lessons during the pandemic & Application for improvement of CHD care \\
\hline 2 & $\begin{array}{l}\text { Triaging patients; discussing hard decisions with family } \\
\text { regarding use of advanced care ventilation and extra } \\
\text { corporeal circulation; hard realization that not "everyone can } \\
\text { get on the ship" }\end{array}$ & $\begin{array}{l}\text { Triaging children with complex heart disease and channeling } \\
\text { limited resources to patients with correctable lesions; realization } \\
\text { that not everyone can be saved which helps improve our risk } \\
\text { communication }\end{array}$ \\
\hline 3 & $\begin{array}{l}\text { Increased use of technology, scope of telemedicine and } \\
\text { remote learning }\end{array}$ & $\begin{array}{l}\text { Increase use of telemedicine (where possible); using hand-held } \\
\text { U/S technology and artificial intelligence to diagnose rheumatic } \\
\text { heart disease in the field with physician extenders }\end{array}$ \\
\hline 4 & Consolidation of various services & $\begin{array}{l}\text { The need to look at economies of scale rather than multiple small } \\
\text { cardiac programs }\end{array}$ \\
\hline 6 & $\begin{array}{l}\text { Many new innovations in respiratory support and development } \\
\text { of care protocols vide many partnerships across the world }\end{array}$ & $\begin{array}{l}\text { Frugal innovation for cost effective cardiac care; expand } \\
\text { partnerships with industry and/or public-private partnerships e.g., } \\
\text { develop low-cost capital equipment and disposables }\end{array}$ \\
\hline 7 & Speed at which vaccines were developed & $\begin{array}{l}\text { Penicillin availability for RHD secondary prophylaxis (and other } \\
\text { critical medicines) }\end{array}$ \\
\hline 8 & $\begin{array}{l}\text { High usage of websites such as Centers for Disease Control, } \\
\text { World Health Organization etc. for evolving protocols of care }\end{array}$ & $\begin{array}{l}\text { Portals specific for pediatric cardiac surgery for LMICs can be } \\
\text { developed and websites such as CTSNet can include more } \\
\text { global platforms }\end{array}$ \\
\hline
\end{tabular}

CHD, congenital heart disease; RHD, rheumatic heart disease; LMIC, low- and mid-income country.

treatment. If we were to go by the European Association of Cardiothoracic Surgeon's guidelines, an ideal situation would be to have one pediatric cardiac center for every 46 million population (28). Extrapolating the same standard, India would need over 200 dedicated pediatric heart centers to deal with the current burden of CHD. However, there are less than 25 dedicated pediatric cardiac centers currently. The gap is even wider in many low-income countries where there is not even one center that can cater to children with CHD. Hence, not all LMICs can be grouped together based on gaps. The scope of "sustainable pediatric cardiac workforce" for LMICs is extensively documented in literature including by the authors $(8,29-31)$. It is repetitive and beyond the scope of this paper to discuss the same. The gaps include the need for workforce (pediatric cardiac surgeons per population, various staff e.g., anesthesia, critical care, perfusion, biomedical engineer, cardiologist, nurses, consultants etc.), infrastructure, service delivery, financing, information and technology, governance, and advocacy $(29,30)$. The purpose of this article to address how we can use the time available during the COVID-19 pandemic to reduce some of the obvious gaps.

A gap analysis includes the steps needed to move from the present state to a desired future state. We performed a gap analysis to understand the areas that need improvement to help achieve the SDG 2030 goals. In the current state, there is a large dependence on short-term mission teams or other private organizations for cardiac surgeries (31). The common belief is that the focus of the governments in LMICs is often on primary health care given limited resources and fewer resources are diverted towards providing tertiary care that is often considered a luxury. As such, in order to address the growing numbers of patients who require specialty care, private organizations have partnered with local hospitals to provide the necessary care in the form of short-term missions with visiting teams, often from Europe and North America. Another consequence of the lack of specialty centers is the long waitlist for CHD surgery in LMICs with limited cardiac surgery facilities. 


\section{Future state}

Ideally, LMICs need to begin developing their own selfsustaining programs from local grass-roots hospitals and organizations based on the geopolitical, economic and social factors (32). Few programs in Namibia, Uganda, and Zambia have been functioning despite bottlenecks and gaps (33). Working towards creating public-private partnerships (PPP) would allow for increased utilization of available government resources in the healthcare sectors and promote synergy between existing public and private sectors. Local partnerships would also greatly benefit specialty centers, as it would improve the availability of resources and decrease temporal and geographical barriers. Frugal innovation may be necessary, based on the local resources. Frugal innovation is defined by Zeschky et al. as "good-enough, affordable products that meet the needs of resource-constrained consumers" (34). The other definition is "means or ends, to do more with less, for the many" (35). Standardizing a method of triaging CHD patients would allow for distribution of resources based on the complexity and operability of the congenital lesion. A proper referral system will be helpful in a resource-limited state.

\section{Gap}

Currently, we remain far from reaching the ideal "future state" in cardiac care in LMICs. The current number of programs in LMICs is insufficient to address the growing need for cardiac care, which continues to exacerbate the already growing waitlist of patients who are unable to receive proper care (36).

Because many LMICs are still battling communicable illnesses, NCDs are not a priority. The common impression is that pediatric heart surgery is very resource intensive and expensive. For example, in the African continent, there are very few established congenital heart centers outside of a handful of countries. Contrary to this popular belief, studies have shown that surgery is cost effective when taking into consideration the potential gains in life expectancy, years of schooling, gross national income for each survivor and the fact that many do have correctible lesions and may need one time operation $(37,38)$. The cost effectiveness of cardiac surgery in the developing world is estimated to be $\$ 171$ per DALY (37). As of 2014, a survey identified 80 NGOs that provide missions for CHD surgery to LMICs with reasonable outcomes (39).

In addition to cost consideration, there is a need for more standardized training programs, certification processes, and mentoring of surgeons. Many surgeons from LMICs are trained overseas in Western Europe or North America, and return to be disappointed by the lack of resources. To add, the lack of supportive staff in the form of specialized ICU trained nurses, cardiac anesthetists, biomedical engineers, and perfusionists (amongst others) demoralizes the team (4).

To complicate the above resource gap is the devastation of COVID-19, which has forced LMICs to divert their limited health care resources to tackling the pandemic, causing a major gap in the care of children with CHD $(9,10,40-42)$. The treatment modalities of the COVID infection are highly debated, and in most cases, very expensive and beyond the reach of many in LMICs. Appropriately, the attention is diverted towards prevention. A reasonable "end goal" is mass vaccination and making COVID-19 a notifiable disease, coupled with herd immunity (18). However, vaccinations are still beyond the reach of many LMICs, as there are widespread vaccine shortages. It can be reasonably assumed that it will be at least several years before the goal of vaccination can be achieved in LMICs. This is the biggest gap for safe resumption of full cardiac care in LMICs.

Lastly, the lack of division of labor between secondary and tertiary hospitals leads to decreased efficiency and longer wait times. Without a network of hospitals to communicate with one another for referrals and to delegate the necessary patients to the "best-fit" center, the patient waitlist will only grow. The LMICs are all very diverse countries, including India, Brazil, and China where there are some high performing cardiac centers, also included are countries such as Haiti and Congo where there are obvious deficiencies. Hence, some of the concepts we discuss may not be applicable where there are no centers taking care of patients with CHD.

\section{SWOT analysis}

Here we attempt to do a SWOT analysis, using the pandemic as an opportunity to fast track the care of children with CHD (Figure 1). We discuss the strengths, weaknesses, opportunities, and threats for CHD care in LMIC. Traditionally, strengths and weaknesses are supposed to be under internal control, while opportunities and threats are external (environmental). Here, the COVID-19 pandemic is the primary externality. We do believe that the pandemic can stimulate achievement of the goals of SDG by 2030 in LMICs. 


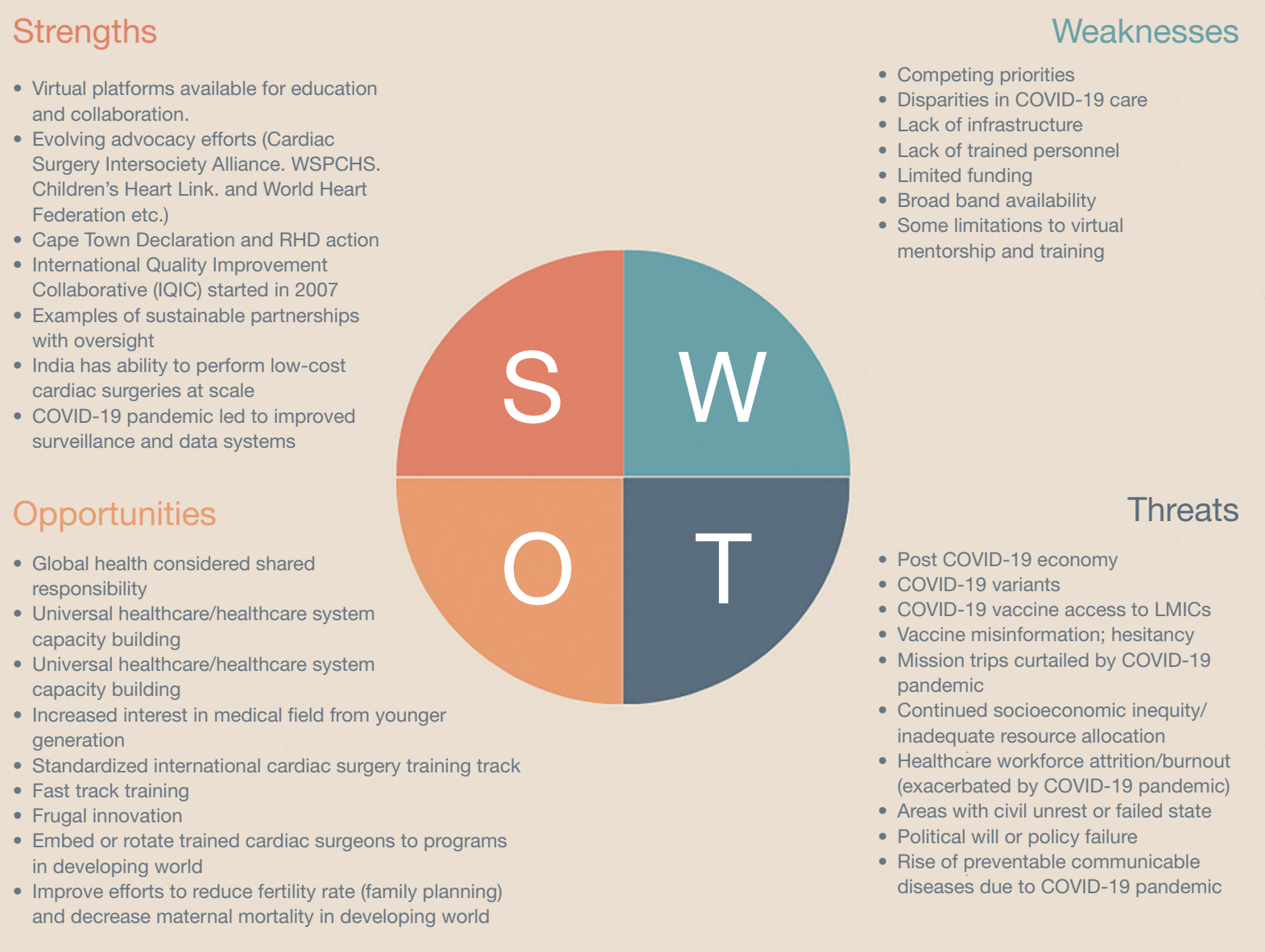

Figure $1 \mathrm{SWOT}$ ( $\mathrm{S}=$ strengths, $\mathrm{W}=$ weaknesses, $\mathrm{O}=$ =pportunities, $\mathrm{T}=$ threats) analysis using the pandemic as an opportunity to fast track the care of children with CHD. CHD, congenital heart disease.

\section{Strengths}

Strengths are usually the areas we do well in and the advantages we have. The world has come together as a "global village" because of the COVID-19 pandemic. Countries are uniting in the fight against COVID-19 pandemic, as the virus has not discriminated against whom it affects. With advances in technology, such as the use of virtual platforms like ZOOM, it has become easier to share information and disseminate knowledge globally at a rapid pace. Academic conferences have moved to online platforms, allowing for much higher levels of attendance than previously. As such, the pandemic has provided an arena for sharing knowledge globally without the barriers of travel, space, and time. All trainees and colleagues, regardless of nation, socioeconomic status, or representation, have equal opportunity to access educational platforms, the impact of which cannot be more stressed (43). Recent conferences such as the AATS has provided a unique opportunity for so many across the world who otherwise could not have afforded to travel for the conference (43). The Indian Association of Cardiovascular and Thoracic Surgeons (IACTS) has organized one of the largest educational initiatives in the world called "MASTERCLASS" during the pandemic lockdown period $(44,45)$. As per Dr. Hiremath, the secretary of IACTS, they conducted over 400 live Zoom sessions conducted by worldwide faculty, which were attended by hundreds of cardiac surgery professionals from 23 countries (46). The topics covered all aspects of adult and pediatric cardiothoracic surgery and they are in the process of publishing all of them online soon. Portals such as CTS net also provided many sessions for global learning (47). 
The pandemic gives us a perfect opportunity for advocacy efforts and for serious consideration of all the goals made in the pre-pandemic era in the form of the Cape Town declaration and joint efforts by various societies. The pandemic has also provided us with the basic frameworks for triaging patients efficiently. COVID-19 challenged all existing healthcare infrastructures and pushed hospital systems to operate beyond their baseline capacity, especially when it came to emergency and critical care medicine (48). The lessons learned can be applicable to cardiac surgery. Hospitals that have lower capacity for procedures or less availability of resources can triage CHD patients to focus on simpler cases, such as ASDs and VSDs, and refer complex patients to tertiary centers where possible. If no referral services are available, the pandemic has taught us about having a risk communication or the hard talk with family. The pandemic has also increased the awareness of the use of surveillance and data systems.

\section{Weaknesses}

Weaknesses are usually the areas, which require improvement. The COVID-19 pandemic has had a significant effect on the existing congenital heart surgery programs all around the world $(9,10,40-42)$. Many countries are still recuperating from sustained collateral damages from the pandemic. Because of this, many countries are forced to shift all their resources towards the COVID-19 pandemic, and do not have the luxury to distribute healthcare resources to other needs, including cardiac surgery. As such, care towards specialties such as cardiac care and CHD has been greatly diluted (49).

The pandemic has affected low-resource settings severely and is compounded by the lack of vaccine availability in the majority of LMICs (50). The pandemic exacerbated hospitals in low-resource settings, as many hospital systems were overwhelmed with the exponentially increasing volumes of COVID patients without the infrastructure to support these patients or provide the necessary care to treat them. The pandemic also magnified already existing blatantly apparent and vulnerable gaps in healthcare infrastructure across the globe. The pandemic has stretched the existing infrastructures inside out. Funding, personnel, and infrastructure form the crux of all weaknesses.

\section{Opportunities}

The opportunities usually include external factors that help and contribute to the strengths. The COVID-19 pandemic has provided an opportunity to empower local communities. During the early days of the pandemic, many hospitals had inadequate staff to face the exponentially increasing numbers of COVID-19 patients. However, the systems quickly adapted and trained redistributed health workers from other specialties. From this need emerged an answer: developing rapid training for nurses and other healthcare workers to tackle the incoming number of COVID patients (51). As nurses and healthcare workers continued to staff COVID units, efficient training systems evolved to streamline the training process for nurses with little wastage of time between training and working. There is also a greater interest amongst the younger generation for healthcare professions. The pandemic has provided us opportunities for global partnerships, fostering healthcare capacity building, creating training platforms, working out curriculums for training, and embracing technology. Prevention of RHD and maternal health education can become a priority. Similarly, implementing rapid training of all professionals in the setting of cardiac programs, using more virtual platforms, incorporating telemedicine and creating more PPPs can all help with care of children with CHD and to achieve the SDG 2030 goals.

\section{Threats}

Threats are potential risks and problems caused by external factors. The prospective course of the COVID-19 pandemic is still unknown. Many LMICs may go through a post pandemic economic slump and recession, which will be a threat to care. With many of the variants now dominating as formidable forces, including the new Delta variant that emerged with a second wave in India, it has become difficult for epidemiologists and scientists to predict the course of the virus and the pandemic (52). As such, the state of affairs about cardiac surgery missions that supported many of the cardiac programs in LMICs will continue to be in limbo. Hospital systems will also need to continue redirecting resources to address hospital burdens secondary to the effects of the coronavirus. For hospitals that are unable to effectively take on the burdens of the pandemic, this will be a huge threat to currently existing infrastructures.

Vaccine shortage, vaccine hesitancy, vaccine misinformation, newer variants and healthcare system "fatigue" are all threats that can delay care of children with CHD. Widespread delivery of vaccines, effective monitoring systems, and a greater understanding of the 
virus may be the only way to observe and manage the consequences of the current pandemic.

To this end, we believe that the strengths outweigh the weaknesses. The world can maximize the opportunities provided to us from the pandemic by using the strengths and lessons learned from the pandemic to focus on converting the existing weaknesses to our strengths and minimizing the threats. Doing so will help us achieve the SDG goals by 2030 despite having lost valuable time.

\section{Action plan for the gap analysis during the pandemic}

The first thing that needs to be addressed is controlling the damage due to the COVID-19 pandemic. Without doing so, there will be no means to address the global disparities in cardiac care.

Finding ways to provide vaccine accessibility to LMICs is of utmost priority to decrease the burden of COVID-19 in the healthcare sector. Thankfully, studies have shown that there is less vaccine hesitancy in LMICs and vaccination of $60 \%$ of population may result in some herd immunity (53). However, vaccine shortages in LMICs will delay efforts of fully vaccinating population. The World Bank has recently called for action to address the issue (54). While the control measures are in place, the collateral damage needs assessment and necessary amends made to tackle the gaps that exist between the present state and the desired, future state of cardiac surgery globally.

For the next few years, while the world is battling the pandemic and working towards universal vaccination, much can be done to fill the gaps we identified above and equip LMICs to provide care for children with CHD. Possible actions could be the following:

\section{Utilization of virtual platforms}

The pandemic has taught us that much about use of virtual training. What was thought to be impossible years ago is now a reality. The same technology can be used to standardize surgical training, use visuals, videos and live streaming (where technology permits). This can potentially be utilized to help create an international standard for cardiac surgical training (55).

\section{Learning curve}

We all know that the so-called learning curve for some surgeries, such as an arterial switch, is no longer a reality, as it is ethically unacceptable (56). So, how can the new surgeons be trained? A lot is achieved by assisting and mentoring process. However, significant achievements can be made by using high-quality digital videos, simulation, and practice on animal heart specimens or 3-D models (where technology permits). As has always been the case, a mentor is required who is willing to take less experienced surgeons step-by-step (and safely) through these procedures.

\section{Frugal innovation}

There continues to exist the impression that heart surgery requires many resources and money. Here comes the notion of the "economies of scale" and "Frugal Innovation". Frugal innovation in cardiac surgery may help in innovation by allowing indigenous production of essential items and reducing the cost. The question is whether LMICs can adopt a strategy used by Narayana Hrudayalaya or Arvind eye hospital model: the "Henry Ford conveyer belt" model (57). In the long run, they may be more economically feasible. Frugal innovation models can act as an anchor at this moment (57). One of the finest examples of frugal innovation is the production of cost effective Chitra heart valves, which are being used in many LMICs (58).

\section{Training and more training}

As mentioned above, the lack of established congenital heart centers, structured training, certification process, and mentoring in LMICs, especially in the African continent, makes it difficult to improve cardiac care. This gap can and must be narrowed. Much can be achieved remotely through virtual trainings (43). This is probably the right opportunity to work towards one of the goals of the Cape Town declaration by training cardiac surgeons in Africa (15). Efforts should also be made to simultaneously train nurses, anesthesiologists, perfusionists, pediatric cardiologists, intensivists etc.

\section{Standardized curriculum}

Partnerships with large programs, charities and associations may help in coming up with a standardized training program. It needs to be emphasized that some of the regulatory requirements that exist in developed nations may not be ideal for LMICs. Affordable models such as the ones in India, China, Malaysia, and Vietnam are some of the 
models that may better suit LMICs. The Global Council on Education for Congenital Heart Surgery, the World Society of Pediatric and Congenital Heart Surgery (WSPCHS), Society of Thoracic Surgeons (STS), European Association for CardioVascular and Thoracic Surgery (EACTS), and Asian Society of Cardiovascular and Thoracic Surgery (ASCVTS) can all take a lead on this issue.

\section{Embedding}

We have written about the same in the past (8). This is valuable in the current era. A "spark plug" is necessary to advocate for each program. We do believe that this is very important for the success of future programs. We need somebody locally who is interested to in taking the program forward. Strength comes from "within" rather than from "without".

\section{Training portal}

A training portal like CTSNet specifically for LMICs, should be developed. A cue can be taken from the 'Masterclass' sessions organized by the IACTS as discussed earlier. This can be used for training and coaching purpose for surgeons and other allied specialties. This can give access for virtual operative videos, virtual operative description, and protocols.

\section{Training nurses}

Nurses were the backbone for care during the Spanish flu pandemic. In similar ways, during the present COVID pandemic they have risen up to the occasion and served well. Many nurses who were primary care nurses and community nurses underwent rapid training and became "emergency and critical care COVID nurses". In many parts of the world, nurses were upskilled very quickly to fill the role of ICU nurses to take care of COVID patients. In the same way, cardiac nursing training could be done virtually (51).

\section{Medical curriculum}

Efforts need to be made in LMICs to integrate public health into medical education. Producing health professionals who are mindful of social determinants of health and desire to work towards overall health improvement, screening and health delivery are the need of the hour (26).

\section{"Brave New World"}

In a recent publication, the authors ask a question, "Are we brave enough to embrace the new world, which requires paradigm shifts"? The pandemic, which has been an oncein-a-lifetime opportunity, is truly a brave new world. We have learned the nuances of the virtual space. Can we push the boundaries to use the space to virtually mentor surgeons, improve ICU care, and provide logistical and medical care as we envision a braver new world (43)?

\section{Conclusions}

Our Gap and SWOT analysis create an action plan with a lens on developing a sustainable pediatric cardiac workforce to move towards the SDG 2030. The COVID-19 pandemic led to a significant and widespread healthcare disruption. However, some innovations, which came in part due to the pandemic, can be leveraged to help reach our goals. As the old saying goes, "If we continue doing the way we always did, we will get the same results we always got". Perhaps the pandemic has forced us to move away from the mentality of accepting a sometimes-dysfunctional status quo and provided the necessary "jump start" for achieving the SDG 2030 goals of "[ensuring] healthy lives and [promoting] well-being for all at all ages" within the next decade. There are still nine years until 2030. The course of the pandemic is still very uncertain with newer variants causing havoc across the world. The COVID-19 pandemic may also fulfill the definition of "disruptive innovation" coined by the late Clayton Christensen and provide the much-needed acceleration to improve health care systems in LMICs in the ensuing years.

\section{Acknowledgments}

Funding: None.

\section{Footnote}

Provenance and Peer Review: This article was commissioned by the Guest Editors (Dominique Vervoort and Marcelo Cardarelli) for the series "Addressing Global Disparities in Pediatric and Congenital Cardiac Care" published in $A M E$ Surgical fournal. The article has undergone external peer review.

Peer Review File: Available at https://asj.amegroups.com/ article/view/10.21037/asj-21-72/prf 
Conflicts of Interest: All authors have completed the ICMJE uniform disclosure form (available at https://asj.amegroups. com/article/view/10.21037/asj-21-72/coif). The series "Addressing Global Disparities in Pediatric and Congenital Cardiac Care" was commissioned by the editorial office without any funding or sponsorship. The authors have no other conflicts of interest to declare.

Ethical Statement: The authors are accountable for all aspects of the work in ensuring that questions related to the accuracy or integrity of any part of the work are appropriately investigated and resolved.

Open Access Statement: This is an Open Access article distributed in accordance with the Creative Commons Attribution-NonCommercial-NoDerivs 4.0 International License (CC BY-NC-ND 4.0), which permits the noncommercial replication and distribution of the article with the strict proviso that no changes or edits are made and the original work is properly cited (including links to both the formal publication through the relevant DOI and the license). See: https://creativecommons.org/licenses/by-nc-nd/4.0/.

\section{References}

1. Hoffman JIe. The global burden of congenital heart disease. Cardiovasc J Afr 2013;24:141-5.

2. Saxena A. Status of Pediatric Cardiac Care in Developing Countries. Children (Basel) 2019;6:34.

3. Hewitson J, Zilla P. Children's heart disease in subSaharan Africa: challenging the burden of disease. J South Afr Heart Ass 2010;7:18-29.

4. GBD 2017 Congenital Heart Disease Collaborators. Global, regional, and national burden of congenital heart disease, 1990-2017: a systematic analysis for the Global Burden of Disease Study 2017. Lancet Child Adolesc Health 2020;4:185-200.

5. Watkins DA, Johnson CO, Colquhoun SM, et al. Global, Regional, and National Burden of Rheumatic Heart Disease, 1990-2015. N Engl J Med 2017;377:713-22.

6. Bode-Thomas F. Challenges in the management of congenital heart disease in developing countries. Congenital Heart Disease -Selected Aspects. InTechOpen 2012:263-72.

7. Tchervenkov CI, Herbst C, Jacobs JP, et al. Current Status of Training and Certification for Congenital Heart Surgery Around the World: Proceedings of the Meetings of the Global Council on Education for Congenital Heart
Surgery of the World Society for Pediatric and Congenital Heart Surgery. World J Pediatr Congenit Heart Surg 2021;12:394-405.

8. Murala JSK, Karl TR, Pezzella AT. Pediatric Cardiac Surgery in Low-and Middle-Income Countries: Present Status and Need for a Paradigm Shift. Front Pediatr 2019;7:214.

9. Shi G, Huang J, Pi M, et al. Impact of early Coronavirus Disease 2019 pandemic on pediatric cardiac surgery in China. J Thorac Cardiovasc Surg 2021;161:1605-1614.e4.

10. Atalay A, Soran Türkcan B, TaşoğluII İ, et al. Management of congenital cardiac surgery during COVID-19 pandemic. Cardiol Young 2020;30:1797-805.

11. SDG Indicators [Internet]. United Nations. United Nations; [cited 2021 Jul 15]. Available online: https:// unstats.un.org/sdgs/report/2020/goal-03/

12. COVID-19 significantly impacts health services for noncommunicable diseases [Internet]. World Health Organization. World Health Organization; [cited 2021 Jul 15]. Available online: https://www.who.int/news/item/0106-2020-covid-19-significantly-impacts-health-servicesfor-noncommunicable-diseases

13. Sanders J, Akowuah E, Cooper J, et al. Cardiac surgery outcome during the COVID-19 pandemic: a retrospective review of the early experience in nine UK centres. J Cardiothorac Surg 2021;16:43.

14. Fattouch K, Corrao S, Augugliaro E, et al. Cardiac surgery outcomes in patients with coronavirus disease 2019 (COVID-19): A case-series report. J Thorac Cardiovasc Surg 2020:S0022-5223(20)32872-5.

15. Zilla P, Bolman RM, Yacoub MH, et al. The Cape Town Declaration on Access to Cardiac Surgery in the Developing World. Cardiovasc J Afr 2018;29:256-9.

16. SDG Goal 3 । Department of Economic and Social Affairs [Internet]. United Nations. United Nations; [cited 2021 Jul 14]. Available online: https://sdgs.un.org/goals/goal3

17. Martini M, Gazzaniga V, Bragazzi NL, et al. The Spanish Influenza Pandemic: a lesson from history 100 years after 1918. J Prev Med Hyg 2019;60:E64-7.

18. Patterson GE, McIntyre KM, Clough HE, et al. Societal Impacts of Pandemics: Comparing COVID-19 With History to Focus Our Response. Front Public Health 2021;9:630449.

19. Zhang Y, Olufadewa II, Adesina MA, et al. Lessons from the coronavirus disease 2019 (COVID-19) pandemic response in China, Italy, and the U.S.: a guide for Africa and low- and middle-income countries. Glob Health J 2021;5:56-61. 
20. Video conferencing, Cloud Phone, WEBINARS, Chat, Virtual EVENTS: ZOOM [Internet]. Zoom Video Communications. [cited $2021 \mathrm{Aug}$ 27]. Available online: https://zoom.us/

21. Koplan JP, Bond TC, Merson MH, et al. Towards a common definition of global health. Lancet 2009;373:1993-5.

22. Labonté R, Mohindra K, Schrecker T. The growing impact of globalization for health and public health practice. Annu Rev Public Health 2011;32:263-83.

23. Rosso A, Civitelli G, Marceca M. Global health, international health and public health: which relationship? Ann Ig 2012;24:263-7.

24. Büyüm AM, Kenney C, Koris A, et al. Decolonising global health: if not now, when? BMJ Glob Health 2020;5:e003394.

25. James HK, Pattison GTR. Disruption to Surgical Training during Covid-19 in the United States, United Kingdom, Canada, and Australasia: A Rapid Review of Impact and Mitigation Efforts. J Surg Educ 2021;78:308-14.

26. Maeshiro R, Koo D, Keck CW. Integration of public health into medical education: an introduction to the supplement. Am J Prev Med 2011;41:S145-8.

27. Saxena A. Pediatric cardiac care in India: current status and the way forward. Future Cardiol 2018;14:1-4.

28. Daenen W, Lacour-Gayet F, Aberg T, et al. Optimal Structure of a Congenital Heart Surgery Department in Europe: by EACTS Congenital Heart Disease Committee. Euro J Card Thorac Surg 2003;24:343-51.

29. Vervoort D, Swain JD, Pezzella AT, et al. Cardiac Surgery in Low- and Middle-Income Countries: A State-of-the-Art Review. Ann Thorac Surg 2021;111:1394-400.

30. Vervoort D, Zheleva B, Jenkins KJ, et al. Children at the Heart of Global Cardiac Surgery: An Advocacy Stakeholder Analysis. World J Pediatr Congenit Heart Surg 2021;12:48-54.

31. Polivenok I, Gelatt M, Cardarelli M. Cardiac surgical missions: what works, what does not, where we need to go from here. Curr Opin Cardiol 2020;35:76-9.

32. Paul E, Brown GW, Ridde V. COVID-19: time for paradigm shift in the nexus between local, national and global health. BMJ Glob Health 2020;5:e002622.

33. Forcillo J, Watkins DA, Brooks A, et al. Making cardiac surgery feasible in African countries: Experience from Namibia, Uganda, and Zambia. J Thorac Cardiovasc Surg 2019;158:1384-93.

34. Zeschky M, Widenmayer B, Gassmann O. Frugal innovation in emerging markets. Res Tech Mangmt
2011;54:38-45.

35. Bhatti YA, Ventresca M. How can 'frugal innovation' be conceptualized? [Internet]. SSRN. 2013 [cited 2021Jul27]. Available online: https://ssrn.com/abstract $=2203552$

36. Zilla P, Yacoub M, Zühlke L, et al. Global Unmet Needs in Cardiac Surgery. Glob Heart 2018;13:293-303.

37. Cardarelli M, Vaikunth S, Mills K, et al. Cost-effectiveness of Humanitarian Pediatric Cardiac Surgery Programs in Low- and Middle-Income Countries. JAMA Netw Open 2018;1:e184707.

38. Fenton KN, Cardarelli M, Molloy F, et al. Ethics in humanitarian efforts: when should resources be allocated to paediatric heart surgery? Cardiology in the Young. Cambridge University Press 2019;29:36-9.

39. Nguyen N, Jacobs JP, Dearani JA, et al. Survey of nongovernmental organizations providing pediatric cardiovascular care in low- and middle-income countries. World J Pediatr Congenit Heart Surg 2014;5:248-55.

40. Luciani GB. Commentary: Lights and shadows of pediatric cardiac surgery in China during the coronavirus disease 2019 pandemic. J Thorac Cardiovasc Surg 2021;161:1616-7.

41. Giamberti A, Varrica A, Agati S, et al. Impact of the coronavirus disease 2019 (COVID-19) pandemic on the Italian congenital cardiac surgery system: a national survey. Eur J Cardiothorac Surg 2020;58:1254-60.

42. Stephens EH, Dearani JA, Guleserian KJ, et al. COVID-19: Crisis management in congenital heart surgery. J Thorac Cardiovasc Surg 2020;160:522-8.

43. Vervoort D, Dearani JA, Starnes VA, et al. Brave New World: Virtual conferencing and surgical education in the Coronavirus Disease 2019 era. J Thorac Cardiovasc Surg 2021;161:748-52.

44. The Indian Association of Cardiovascular and Thoracic surgeons (IACTS). Available online: https://www.iacts. org/content/virtual-masterclass-congenital-heart-defects (accessed September 3, 2021).

45. Murala J, Mathew A, Cherian K. On Location: India. CTSNet. Available online: https://www.ctsnet.org/article/ location-india (accessed September 3, 2021).

46. 67th IACTSCON: A Virtual Symposium [Internet]. Iactscon2021.com. [cited 2021 Oct 15]. Available online: http://www.iactscon2021.com/index.html

47. The cardiothoracic surgery network [Internet]. CTSNet. [cited 2021 Aug 27]. Available online: https://www. ctsnet.org/

48. Ehni HJ, Wiesing U, Ranisch R. Saving the most lives-A comparison of European triage guidelines in the context of 
the COVID-19 pandemic. Bioethics 2021;35:125-34.

49. Einstein AJ, Shaw LJ, Hirschfeld C, et al. International Impact of COVID-19 on the Diagnosis of Heart Disease. J Am Coll Cardiol 2021;77:173-85.

50. Li Bassi L. Allocating COVID-19 Vaccines globally: an urgent need. JAMA Health For 2021;2:e210105.

51. Robinson KR. Comparing the Spanish flu and COVID-19 pandemics: Lessons to carry forward. Nurs Forum 2021;56:350-7.

52. Adam D. What scientists know about new, fast-spreading coronavirus variants. Nature 2021;594:19-20.

53. Bhopal S, Nielsen M. Vaccine hesitancy in low- and middle-income countries: potential implications for the COVID-19 response. Arch Dis Child 2021;106:113-4.

54. Call to Action on COVID Vaccine access for developing countries by heads of World Bank Group and International
Monetary Fund [Internet]. World Bank. [cited 2021Jul16]. Available online: https://www.worldbank.org/en/ news/statement/2021/06/03/world-bank-group-andinternational-monetary-fund-call-to-action-on-covidvaccine-access-for-developing-countries

55. Yoo SJ, Spray T, Austin EH 3rd, et al. Hands-on surgical training of congenital heart surgery using 3-dimensional print models. J Thorac Cardiovasc Surg 2017;153:1530-40.

56. Beckerman Z, Mery CM. Teaching congenital heart disease: A new era? J Thorac Cardiovasc Surg 2017;153:1541.

57. Bhatti Y, Taylor A, Harris M, et al. Global Lessons In Frugal Innovation To Improve Health Care Delivery In The United States. Health Aff (Millwood) 2017;36:1912-9.

58. Valiathan MVS. Frugal innovation in cardiac surgery. Indian J Thorac Cardiovasc Surg 2018;34:439-48. doi: $10.21037 /$ asj-21-72

Cite this article as: Murala JSK, Kim S, Karl TR, Pezzella AT. Fostering a sustainable pediatric cardiac workforce in the developing world during the current COVID-19 pandemic. AME Surg J 2022;2:5. 